\title{
REPRESENTAÇÕES SOCIAIS DE ESTUDANTES DO NONO ANO DO ENSINO FUNDAMENTAL SOBRE LEITURA E ESCRITA
}

Lucilia Vernaschi de Oliveira ${ }^{1}$, Solange Franci Raimundo Yaegashi ${ }^{2}$, Simone de Souza ${ }^{3}$, João Gabriel Yaegashi $^{4}$, Tatiana Lemes de Araújo Batista ${ }^{5}$, Bethânia Vernaschi de Oliveira ${ }^{6}$

${ }^{1}$ Doutora em Educação pela Universidade Estadual de Maringá - UEM, PR. Docente do Instituto Federal Tecnológico do Paraná - IFTPR, Campus de Umuarama, Paraná.ORCID iD: http://orcid.org/0000-0003-1356-537X. E-mail: luvernaschi@gmail.com

${ }^{2}$ Doutora em Educação pela Universidade Estadual de Campinas - UNICAMP, SP. Docente do Departamento de Teoria e Prática da Educação e do Programa de Pós-Graduação em Educação da Universidade Estadual de Maringá - UEM, PR. ORCID iD: https://orcid.org/0000-0002-7666-7253. E-mail: solangefry@gmail.com

${ }^{3}$ Doutora em Educação para a Ciência e a Matemática pela Universidade Estadual de Maringá - UEM, PR. Docente do Departamento de Teoria e Prática da Educação da Universidade Estadual de Maringá - UEM, PR. ORCID iD: https://orcid.org/0000-0002-6583-5223. E-mail: simoneejordao@hotmail.com

${ }^{4}$ Mestrando em Ciências Jurídicas pelo Centro Universitário de Maringá - UNICESUMAR, PR. ORCID iD: https://orcid.org/0000-0002-6341-0942. E-mail: igyaegashi@hotmail.com

${ }^{5}$ Mestranda no Programa de Pós-Graduação em Educação da Universidade Estadual de Maringá - UEM, PR. ORCID iD: https://orcid.org/0000-0002-4005-5722. E-mail: tatianalabatista@hotmail.com

${ }^{6}$ Especialista em Educação Especial e Inclusiva pela UNIFEFCV. ORCID iD: https://orcid.org/0000-0002-1006-330X. Email: bth.net@outlook.com

\section{RESUMO}

A presente investigação é fundamentada na Teoria das Representações Sociais (TRS), de Serge Moscovici e apresenta uma abordagem quantiqualitativa na coleta e análise das representações sociais (RS) dos sujeitos pesquisados sobre o ensino sistemático da nossa língua materna trabalhada na Educação Básica. Para isso, traçamos como objetivo investigar as representações sociais de estudantes do nono ano do Ensino Fundamental sobre o ensino-aprendizagem da leitura e escrita. Participaram da pesquisa 37 (trinta e sete) estudantes de duas escolas públicas estaduais, sediadas em um município da região norte do estado do Paraná, sendo 23 (vinte e três) alunos da Escola Central 1 (EC1) e 14 (quatorze) da Escola Periférica 1 (EP1). Os pesquisados responderam a um questionário com 18 (dezoito) questões, sendo 9 (nove) referentes à leitura e 9 (nove) sobre a escrita. Para a apresentação das RS coletadas, elaboramos dois quadros nos quais sintetizamos os dados estatísticos da pesquisa; o primeiro apresenta os aspectos referentes às práticas de leitura dos estudantes, o segundo, por sua vez, demonstra os de leitura. Além disso, de acordo com os pressupostos moscovicianos discutimos qualitativamente as RS obtidas pela pesquisa. De forma geral, as RS dos investigados dão conta de que a maioria deles pouco lê e pouco escreve, o que confirma os resultados das avaliações externas, bem como as queixas de professores, pais e outros profissionais da escola sobre o fraco desempenho escolar dos alunos brasileiros.

Palavras-chave: Teoria das Representações Sociais. Leitura e Escrita. Ensino Fundamental. Estudantes.

\section{SOCIAL REPRESENTATIONS OF STUDENTS OF THE NINTH YEAR OF FUNDAMENTAL EDUCATION ON READING AND WRITING}

\section{ABSTRACT}

The present research is based on Serge Moscovici's Theory of Social Representations (TSR) and presents a quantiqualitative approach in the collection and analysis of the social representations (SR) of the subjects researched on the systematic teaching of our mother tongue worked in Basic Education. For this, we aimed to investigate the social representations of ninth grade students about the teaching and learning of reading and writing. Thirty-seven (37) students from two state public schools, located in a municipality in the northern region of the state of Paraná, participated in the research, being 23 (twenty-three) students from 
Central School 1 (EC1) and 14 (fourteen) from Peripheral School 1 (EP1). The respondents answered a questionnaire with 18 (eighteen) questions, 9 (nine) referring to reading and 9 (nine) about writing. For the presentation of the collected SR, we elaborated two charts in which we synthesized the research statistical data; the first presents the aspects related to the students reading practices, the second, in turn, shows the reading practices. Moreover, according to the Moscovici assumptions we qualitatively discuss the SR obtained by the research. Overall, the SR of the respondent's report that most read and write poorly, which confirms the results of external evaluations, as well as complaints from teachers, parents, and other school professionals about poor brazilian students achievement.

Keywords: Theory of Social Representations. Reading and writing. Elementary School. Students.

\section{REPRESENTACIONES SOCIALES DE ESTUDIANTES DEL NOVENO AÑO DE EDUCACIÓN FUNDAMENTAL SOBRE LECTURA Y ESCRITURA}

\section{RESUMEN}

La presente investigación se basa en la Teoría de las Representaciones Sociales (TRS) de Serge Moscovici y presenta un enfoque cuantitativo-cualitativo en la recopilación y análisis de las representaciones sociales (RS) de los sujetos investigados sobre la enseñanza sistemática de nuestra lengua materna trabajada en Educación Básica. Con este fin, nos propusimos investigar las representaciones sociales de los estudiantes en el noveno grado de la escuela primaria sobre la enseñanza y el aprendizaje de la lectura y la escritura. Participaron en la investigación37 (treinta y siete) estudiantes de dos escuelas públicas estatales, con sede en un municipio de la región norte del estado de Paraná, siendo 23 (veintitrés) estudiantes de la Escuela Central 1 (EC1) y 14 (catorce) de la Escuela de la Periferia 1 (EP1). Los encuestados respondieron un cuestionario con 18 (dieciocho) preguntas, 9 (nueve) de las cuales estaban relacionadas con la lectura y 9 (nueve) con la escritura. Para la presentación de la RS recopilada, creamos dos tablas en las que sintetizamos los datos estadísticos de la investigación; el primero presenta aspectos relacionados con las prácticas de lectura de los estudiantes, el segundo, a su vez, demuestra la lectura. Además, de acuerdo con los supuestos de Moscú, discutimos cualitativamente la RS obtenida por la investigación. En general, los SR de los encuestados informan que la mayoría de ellos leen y escriben poco, lo que confirma los resultados de las evaluaciones externas, así como las quejas de los maestros, padres y otros profesionales escolares sobre el bajo rendimiento escolar de los estudiantes brasileños.

Palabras clave: Teoría de las Representaciones Sociales. Lectura y escritura. Enseñanza Fundamental. Estudiantes.

\section{INTRODUÇÃO}

Para fundamentar esta pesquisa optamos pela Teoria das Representações Sociais (TRS) como pressuposto teórico-metodológico, porque acreditamos que esse referencial é consistente para subsidiar a investigação pretendida, uma vez que ao representar algo ou alguém, o sujeito se coloca na condição do outro, reflete sobre o que está sendo apurado e expõe suas concepções a respeito de tal objeto de conhecimento.

A TRS teve seu marco inicial em 1961 pelo psicólogo social romeno radicado na França, Serge Moscovici (1925-2014). As inquietações iniciais desse autor versavam principalmente em materializar conteúdos científicos da Psicanálise em matéria do senso comum, se valendo, a princípio, de reflexões acerca de conceitos como representações coletivas (RC) de Émile Durkheim para a sua evolução em representações sociais
(RS), por ele engendradas e concretizadas pela comunicação humana, por meio de processos de interações sociais, cunhados nos conteúdos socioculturais e em processos psíquicos de apreensão da realidade.

A preocupação de Moscovici centrou-se eminentemente em dois domínios: a ciência e o senso comum. Para ele, apesar de a epistemologia ser necessária à análise das relações, o senso comum advindo do conhecimento social é salutar para melhor compreensão daquela. Pensando como Moscovici, podemos inferir que as RS de estudantes sobre a aprendizagem da língua materna, nosso objeto de estudo, na modalidade da leitura e escrita, perpassa por esses dois universos, o primeiro, de caráter reificado diz respeito aos conteúdos científicos do bem ler, interpretar e registrar os conhecimentos de 
nosso momento histórico; o segundo, de natureza consensual, concerne ao uso social que estudantes e educadores fazem da língua em seu contexto social. Assim sendo, investigar essas representações, apesar da complexidade que o tema exige, é fundamental para a compreensão da atual conjectura em que se encontra a escola pública. Deste modo, a relevância científica da presente investigação se justifica pela necessidade de fomentação de estudos e pesquisas acerca do desenvolvimento acadêmico em leitura e escrita dos estudantes da educação básica, pois os resultados das avaliações externas e de larga escala indicam que os níveis alcançados não são satisfatórios, principalmente os das escolas públicas periféricas.

Moscovici (1978; 2015), em sua explicação sobre a funcionalidade das representações sociais (RS) esclareceu que elas se encontram distribuídas basicamente nesses dois universos, sendo a preocupação fundante desse pesquisador: compreender como o conteúdo científico era representado consensualmente.

Ainda de acordo com os conceitos fundamentais da TRS, temos a explicação de como os conteúdos sociais são absorvidos e transmitidos pelos sujeitos. Esses processos sociocognitivos são denominados de ancoragem e objetivação (MOSCOVICl, 1978; 2015). Em consonância com esse entendimento, ancorar significa que ao entrar em contato com algo que nos é estranho, buscamos em nosso repertório alguma informação já sedimentada em nossa memória que nos ajuda a entender o novo, e quando conseguimos significar o desconhecido estamos em processo de objetivação.

Nesse sentido, questionamos: como os estudantes investigados representam o ensinoaprendizagem sistematizados e ensinados pela escola, por meio da leitura e escrita? Para responder a essa situação-problema objetivamos investigar as RS de estudantes do nono ano do Ensino Fundamental sobre 0 ensinoaprendizagem da leitura e escrita.

\section{DELINEAMENTO METODOLÓGICO}

Assim como apresentamos, esta investigação é fundamentada na TRS, de Serge Moscovici e apresenta uma abordagem quantiqualitativa. A parte quantitativa se refere aos dados estatísticos decorrentes da tabulação e análise de questionários respondidos por estudantes e a qualitativa diz respeito à interpretação e discussão das RS obtidas nesses instrumentos.

Participaram da pesquisa empírica 37 (trinta e sete) estudantes de duas turmas de nono ano do Ensino Fundamental, de duas escolas públicas estaduais localizadas na região norte do estado do Paraná, realizada no ano de 2017, sendo 23 (vinte e três) deles da instituição que nominamos de Escola Central 1 (EC1) por estar situada na região central da cidade, e 14 (quatorze) de uma escola mais afastada do centro, a qual denominamos de Escola Periférica 1 (EP1). Mediante a aprovação do Comitê de Ética (parecer n. 1.899.348 CAAE 63067416.4.0000.0104) e da autorização dos pais/responsáveis, os participantes responderam a um questionário contendo 18 (dezoito) questões sobre as RS de ensino e aprendizagem da nossa língua materna ensinada na escola em todas as disciplinas curriculares, sendo 09 (nove) delas referentes às práticas de leitura e 09 (nove) sobre a escrita. Para melhor apresentar os dados da pesquisa, elaboramos dois quadros com os questionamentos feitos aos educandos e as respectivas respostas transformadas em linguagem estatística. No Quadro 1 reunimos as RS dos pesquisados resultantes da primeira parte do questionário, que versam sobre as concepções dos nonos anos sobre a leitura ensinada em todas as disciplinas do currículo desse ano escolar. De forma semelhante, no Quadro 2 sintetizamos as respostas da segunda parte do questionário respondido sobre escrita interdisciplinar.

Na sequência, apresentamos a análise e discussão da primeira parte do questionário, na qual os estudantes da EC1 e EP1 inferiram sobre as suas próprias RS e a de seus colegas de turma a respeito da leitura.

\section{REPRESENTAÇÕES SOCIAIS SOBRE O ENSINO- APRENDIZAGEM DE LEITURA}

O Quadro 1 é formado por RS de 23 (vinte e três) estudantes da EC1, e à direita é constituído pelas RS de 14 (quatorze) alunos da EP1, correspondente à primeira parte do questionário com 9 (nove) questões referentes ao ensino-aprendizagem de leitura. 
Quadro 1. Dados percentuais das Representações Sociais de estudantes do nono ano sobre leitura

\begin{tabular}{|c|c|c|c|c|c|}
\hline \multicolumn{6}{|c|}{ REPRESENTAÇÕES SOCIAIS DE ESTUDANTES DO NONO ANO SOBRE LEITURA } \\
\hline \multicolumn{3}{|c|}{ EC1 -23 estudantes } & \multicolumn{3}{|c|}{ EP1 -14 estudantes } \\
\hline №. & Questionamentos & Respostas & №. & Questionamentos & Respostas \\
\hline 01 & Gosto pela leitura & $\begin{array}{l}8(34,8 \%) \text { gostam de ler; } 2(8,7 \%) \\
\text { não gostam; } 13(56,5 \%) \text { às vezes; } \\
15(65,2 \%) \text { não gostam ou não } \\
\text { têm hábito à leitura. }\end{array}$ & 01 & Gosto pela leitura & $\begin{array}{l}2(14,3 \%) \text { gostam de ler; } 4(28,6 \%) \text { não } \\
\text { gostam; } 8(57,1 \%) \text { leem às vezes; } 12 \\
(85,7 \%) \text { não gostam ou não têm } \\
\text { hábito à leitura. }\end{array}$ \\
\hline 02 & $\begin{array}{l}\text { Tipo de material } \\
\text { preferem ler }\end{array}$ & $\begin{array}{l}7 \quad(30,4 \%) \text { preferem ler em } \\
\text { material impresso; } 16 \quad(69,6 \%) \\
\text { preferem ler em materiais } \\
\text { digitais. }\end{array}$ & 02 & $\begin{array}{l}\text { Tipo de material } \\
\text { preferem ler }\end{array}$ & $\begin{array}{l}3(21,4 \%) \text { para as formas tradicionais } \\
\text { de leitura; } \mathbf{1 1}(\mathbf{7 8 , 6 \% )} \text { preferem ler em } \\
\text { material impresso. }\end{array}$ \\
\hline 03 & $\begin{array}{l}\text { RS sobre leitura } \\
\text { extraescolar dos } \\
\text { colegas de classe }\end{array}$ & $\begin{array}{l}\text { Nenhum aluno afirmou que seus } \\
\text { colegas leem sempre; } 7(30,4 \%) \\
\text { leem às vezes; } 13(56,5 \%) \text { leem } \\
\text { raramente; } 3(13 \%) \text { acreditam } \\
\text { que os colegas não leem; ou } \\
\text { seja, } 16(69,5 \%) \text { representam } \\
\text { que os colegas não leem fora da } \\
\text { escola. }\end{array}$ & 03 & $\begin{array}{l}\text { RS sobre leitura } \\
\text { extraescolar dos colegas } \\
\text { de classe }\end{array}$ & $\begin{array}{l}1(7,1 \%) \text { de seus colegas leem sempre } \\
\text { ou de vez em quando; } 10 \text { (71,4\%) } \\
\text { raramente leem; } 2 \text { (14,3\%) não o } \\
\text { fazem fora da escola. Estas } \\
\text { informações dão conta que } \mathbf{1 2}(\mathbf{8 5 , 7 \% )} \\
\text { desconsideram a importância dos } \\
\text { hábitos de estudo extraescolares. }\end{array}$ \\
\hline 04 & $\begin{array}{l}\text { Motivos pelos quais os } \\
\text { colegas de classe leem } \\
\text { pouco }\end{array}$ & $\begin{array}{l}2(8,7 \%) \text { reconhecem que não } \\
\text { são ensinados e motivados ou } \\
\text { não têm acesso a materiais de } \\
\text { leitura; } \mathbf{2 1} \quad(\mathbf{9 1 , 3 \% )} \text { são } \\
\text { responsáveis por não gostar de } \\
\text { ler. }\end{array}$ & 04 & $\begin{array}{l}\text { Motivos pelos quais os } \\
\text { colegas de classe leem } \\
\text { pouco }\end{array}$ & 14 (100\%) não gostam de ler. \\
\hline 05 & $\begin{array}{l}\text { Quantidade de livros } \\
\text { lidos nos últimos dois } \\
\text { anos }\end{array}$ & $\begin{array}{l}3 \text { (13\%) não leram; } 2 \text { ( } 8,7 \%) \text { leu } \\
\text { um livro; nenhum aluno leu dois } \\
\text { livros; } 2(8,7 \%) \text { leram três livros; } \\
8(34,8 \%) \text { leram mais de três } \\
\text { livros; } 2(8,7 \%) \text { não leram; } 6 \\
(26,1 \%) \text { não se lembram; ou } \\
\text { seja, } 65,2 \% \text { dos alunos leem } \\
\text { muito pouco ou não leem. }\end{array}$ & 05 & $\begin{array}{l}\text { Quantidade de livros } \\
\text { lidos nos últimos dois } \\
\text { anos }\end{array}$ & $\begin{array}{l}1(7,1 \%) \text { não leu; } 2 \text { (14,3\%) leram dois } \\
\text { livros; } 1 \text { ( } 7,1 \%) \text { leu três livros; } 4 \\
(28,6 \%) \text { leram mais de três livros; } 3 \\
(21,4 \%) \text { não leram; } 3(21,4 \%) \text { não se } \\
\text { lembram, totalizando } 71,4 \% \text { de } \\
\text { estudantes que leem pouco ou não } \\
\text { leem. }\end{array}$ \\
\hline 06 & $\begin{array}{l}\text { Tipos de livros } \\
\text { preferem ler }\end{array}$ & $\begin{array}{l}\text { Nenhum aluno prefere o livro } \\
\text { didático; } 1 \text { (4,3\%) gosta } \\
\text { autoajuda; } 8(34,8 \%) \text { escolhem } \\
\text { ficção científica; } 10 \text { (43,5\%) } \\
\text { optam por livros de literatura } \\
\text { juvenil; } 4 \text { (17,4\%) escolhem } \\
\text { outra tipologia como: história } \\
\text { em quadrinhos, aventura e } \\
\text { suspense. }\end{array}$ & 06 & $\begin{array}{l}\text { Tipos de livros preferem } \\
\text { ler }\end{array}$ & $\begin{array}{l}\text { Nenhum aluno prefere o livro didático } \\
\text { ou de autoajuda; } 4 \text { (29\%) ficção } \\
\text { científica; } 4 \text { (29\%); literatura; outros } \\
\text { como: suspense, terror, diário, } \\
\text { mistério e gibi correspondem a } 6 \\
\text { (42,9\%) da preferência dos } \\
\text { pesquisados. }\end{array}$ \\
\hline 07 & $\begin{array}{l}\text { Disciplinas que } \\
\text { trabalham } \\
\text { sistematicamente com } \\
\text { leitura em sala de aula }\end{array}$ & $\begin{array}{l}\text { Trabalho constante com leitura: } \\
\text { Arte } 6 \text { (26,1\%); Ciências } 6 \\
(26,1 \%) ; \text { Educação Física } 2(8,7) ; \\
\text { Geografia } 6(26,1 \%) ; \text { História } 15 \\
(65,2 \%) ; \quad \text { Língua Inglesa } 9 \\
(39,1 \%) ; \text { Língua Portuguesa; } 18 \\
(78,3 \%) ; \text { e, matemática } 3(13 \%) .\end{array}$ & 07 & $\begin{array}{l}\text { Disciplinas que } \\
\text { trabalham } \\
\text { sistematicamente com } \\
\text { leitura em sala de aula }\end{array}$ & $\begin{array}{l}\text { Trabalho constante com leitura: Arte } \\
3 \quad(21,4 \%) ; \quad \text { Ciências } 5 \quad(35,7 \%) ; \\
\text { Educação Física } 3(21,4) ; \text { Geografia } 6 \\
(42,9 \%) ; \text { História } 4(28,6 \%) ; \text { Língua } \\
\text { Inglesa } 4(28,6 \%) ; \text { Língua Portuguesa } \\
11(78,6 \%) ; \text { e, matemática } 4(28,6 \%) \text {. }\end{array}$ \\
\hline 08 & $\begin{array}{l}\text { Principais passos e } \\
\text { frequência no estudo } \\
\text { do material lido em } \\
\text { aula }\end{array}$ & $\begin{array}{l}14(60,9 \%) \text { não consultam em } \\
\text { dicionário; } 11 \quad(47,8 \%) \\
\text { leitura silenciosa; } 19 \quad(82,6 \%) \\
\text { realizam leitura oral e coletiva; } 8 \\
(34,8 \%) \text { dos professores } \\
\text { explicam o material lido. }\end{array}$ & 08 & $\begin{array}{l}\text { Principais passos e } \\
\text { frequência no estudo do } \\
\text { material lido em aula }\end{array}$ & $\begin{array}{l}07 \text { (50 \%) não consultam em } \\
\text { dicionário; } 07 \text { (50 \%) realizam leitura } \\
\text { silenciosa; } 7 \text { (50 \%) afirmaram não ser } \\
\text { prioridade aula de leitura oral; } 12 \\
(\mathbf{5 2 , 2 \% )} \text { sugerem eventualidade de } \\
\text { explicação pelo professor do } \\
\text { material; } 3(\mathbf{1 3 \% )} \text { negaram tal prática. }\end{array}$ \\
\hline 09 & $\begin{array}{l}\text { Principais práticas de } \\
\text { leitura em sala de aula }\end{array}$ & $\begin{array}{l}6(26,1 \%) \text { realizam leitura oral } \\
\text { em sala de aula; } 5 \text { (21,7\%) } \\
\text { referiram que as atividades de } \\
\text { leitura realizadas por eles são } \\
\text { silenciosas e orais; } 12 \quad(52,2 \%) \\
\text { que estas atividades são } \\
\text { realizadas por eles e por seus } \\
\text { professores. }\end{array}$ & 09 & $\begin{array}{l}\text { Principais práticas de } \\
\text { leitura em sala de aula }\end{array}$ & $\begin{array}{l}7(50 \%) \text { realizam leitura oral em sala } \\
\text { de aula; } 1(7 \%) \text { realiza leitura oral; } 6 \\
(42,9 \%) \text { assinalaram que realizam } \\
\text { leitura oral e silenciosa tanto por eles } \\
\text { quanto por seus professores. }\end{array}$ \\
\hline
\end{tabular}

Fonte: Os autores.

Nota: Pesquisa de campo própria. 
A primeira questão dirigida aos estudantes sobre o gosto pela leitura foi se "gostam ou não de ler", ou seja, (sim, não ou às vezes). Dos 23 (vinte e três) estudantes da EC1, $8(34,8 \%)$ afirmaram que gostam de ler, $2(8,7 \%)$ disseram não gostar e $13(56,5 \%)$ responderam que às vezes leem. A soma dos dados correspondentes aos que não gostam de ler com os que leem às vezes, nos informa que $15(65,2 \%)$ deles não gostam ou não têm hábito à leitura. Os 14 pesquisados da EP1 afirmaram que $2(14,3 \%)$ gostam de ler, 4 (28,6\%) não gostam e $8(57,1 \%)$ afirmaram que o fazem irregularmente, no entanto, $85,7 \%$ dos estudantes desta escola não gostam ou não têm hábito à leitura.

Dada a importância das práticas leitoras para o desenvolvimento do estudante, as respostas dos pesquisados de que são pouco fluentes em leitura e escrita condizem com os resultados da Prova Brasil (INEP, 2015), em que alcançaram níveis baixos na interpretação do material lido, indicando fraco desempenho na proficiência avaliada. Essa realidade também é consonante com o alto índice de alunos que são aprovados pelo conselho de classe em ambas as escolas.

Os resultados apresentados são preocupantes, no entanto, demonstram uma realidade a ser refletida, visto que, para Moscovici (2015, p. 63), ao se proferir sobre os conceitos de classificação, seja pelo aspecto de generalização ou de particularização, assevera que essa "[...] não é, de algum modo, uma escolha puramente intelectual, mas reflete uma atitude específica com o objeto" (loc. cit); sendo assim, as afirmações ler pouco ou não ler nos trazem informações sobre as RS que os estudantes apresentam sobre suas práticas de leitura, com isso, sinalizam para a premência de reflexões por parte dos envolvidos no processo ensino e aprendizagem sobre esse universo consensual e a necessidade de repensar o trabalho pedagógico e as práticas escolares pelo viés do universo reificado.

A constatação de que os alunos leem pouco aponta uma realidade preocupante a respeito da importância da leitura como instrumento de conhecimento, de lazer, de informação, instrução e outros, e em decorrência disso, há a necessidade de se repensar as práticas reificadas de ensino dessa habilidade linguística, tanto na formação do professor quanto no exercício da docência (OLIVEIRA, 2019).
A segunda indagação feita aos alunos foi sobre em que tipo de material veiculador de leitura preferem ler (impressos ou digitais). Os 7 $(30,4 \%)$ alunos da EC1 demonstraram que ler em material impresso já não os instigam quanto ao ler em meios digitais, que representou $16(69,6 \%)$ da opinião dos pesquisados nessa escola. Por sua vez, os estudantes da EP1 confirmaram seus gostos para leitura em meios digitais, representando $11(78,6 \%)$ deles, e apenas 3 $(21,4 \%)$ para as formas tradicionais de leitura. Apesar da preferência dos pesquisados em ler em meios digitais, constatamos que a escola central não oferecia laboratório de informática ou outros meios de acesso digital aos alunos, já na escola periférica as máquinas do laboratório se mostraram obsoletas. Ainda a esse respeito, precisamos atentar para o fato de que essas novas demandas levaram a mudanças na relação afetiva e cognitiva dos estudantes com os instrumentos culturais, simbólicos ou não.

A respeito dessa nova realidade digital, Matencio (2006, p. 442) pontua que:

[...] na era das mídias, da
Internet e da globalização,
que é também a era do
individualismo
exacerbado, dos guetos,
das gangues, dos
movimentos marginais, a
identidade se constrói por
espaços que são, antes de
tudo, impregnados de
múltiplas linguagens.
Nessa medida, a tentativa
de manter um único
padrão nos usos de
diversos sistemas
semióticos parece ser
inócua.

A conclusão a que chegou Matencio (2006) é a de que não podemos ignorar o momento atual em que os meios de comunicação digitais permeiam a sociedade e a escola, alterando modos de convívio social e criando outros espaços simbólicos de convivência e novas RS.

A terceira pergunta dirigida aos estudantes diz respeito à opinião deles quanto às práticas de leitura dos colegas de classe em espaços extraescolares, por iniciativa própria e sem cobrança da escola. Não houve afirmação quanto à constância desta atividade, e apenas 7 $(30,4 \%)$ deles deduzem que a atividade de leitura 
ocorre às vezes, 13 (56,5\%) afirmaram que acontece raramente e 3 (13\%) acreditam que seus amigos não leem fora da escola, indicado em 16 (69,5\%) dessa negação. A conclusão para esta questão é a de que os estudantes não têm hábito de estudo fora da escola. De forma semelhante, os alunos da EP1 hipotetizam que apenas $1(7,1 \%)$ de seus colegas leem sempre, 0 que é correspondente ao mesmo percentual dos que leem de vez em quando 1 (7,1\%). Acreditam que $10(71,4 \%)$ raramente leem e $2(14,3 \%)$ não o fazem fora da escola. Estas informações dão conta que $12 \quad(85,7 \%)$ desconsideram a importância dos hábitos de estudo extraescolares.

Com base nos pressupostos de Moscovici (2015, p. 210), e em virtude de as RS se manifestarem "[...] como uma "rede" de ideias, metáforas e imagens, mais ou menos interligadas livremente [...]"; possibilita-nos inferir sobre o comportamento de práticas de leitura de seus colegas de turma, levando em consideração, via de regra, sua própria prática não leitora. Ou seja, a imagem que possuem de si é a de que pouco leem, logo, seus colegas de turma também agem como não leitores. Ao se representarem como não leitores, os estudantes objetivam que essa prática de estudo, informação, entretenimento, conhecimento e outros, ainda que inconscientemente, não está atrelada ao seu desenvolvimento acadêmico e pessoal.

A quarta interrogação feita aos estudantes sobre leitura diz respeito, hipoteticamente, aos motivos pelos quais os colegas de classe leem pouco: se simplesmente eles não gostam de ler, se não são ensinados e motivados pelos seus professores sobre os benefícios da leitura no processo de aprendizagem ou se não têm acesso a livros, revistas, jornais e outros materiais escritos impressos e/ou digitais. Enquanto para 100\% dos alunos da EP1 a justificativa de não lerem é centrada neles, ou seja, são os "culpados", pouca coisa se difere das representações da EC1, na qual essa porcentagem é de $21(91,3 \%)$, pois os pesquisados afirmam que os colegas de classe não gostam de ler, e apenas $2(8,7 \%)$ reconhecem que não são ensinados e motivados ou não têm acesso a materiais de leitura. As RS dos estudantes de ambas as escolas pesquisadas é a de que não leem porque não gostam. Entretanto, não atentam para o fato de que o gosto pela leitura é ensinado/aprendido desde muito cedo, e por outro lado, a opção deles, conforme relatamos na questão 2, é a sua realização por meio de materiais digitais, pois são nativos digitais, entretanto, no ambiente escolar o acesso a esses instrumentos tecnológicos é deficitário.

As RS dos pesquisados de ambas as escolas sobre o não gostar de ler fora do ambiente escolar por seus colegas, pode ser compreendida tendo por base que as representações são sociais por serem:

[...] um fato psicológico, de três maneiras: elas possuem um aspecto impessoal, no sentido de pertencer a todos; elas são a representação de outros, pertencente a outras pessoas ou a outro grupo; e elas são uma representação pessoal, percebida efetivamente como pertencente ao ego (MOSCOVICl, 2015, p. 211).

Enfim, os dados estatísticos desta quarta questão estão em conformidade com os resultados da pesquisa "Retratos da Leitura no Brasil" (2016), apontando que a escola pouco contribui no incentivo à leitura dos estudantes brasileiros. Aspecto que condiz com a pouca funcionalidade das bibliotecas escolares, pois os educandos são pouco ensinados e estimulados a usufruir de seu acervo e do ambiente cultural.

A quinta pergunta buscou informações sobre a quantidade de livros o pesquisado leu nos últimos dois anos, indo desde nenhum, não me lembro, um, dois, três ou mais livros. Dos respondentes da EC1, 3 (13\%) afirmaram que nos últimos dois anos não leram livros, $2(8,7 \%)$ leram apenas um, nenhum aluno leu dois livros, 2 $(8,7 \%)$ leram três livros, 8 (34,8\%) asseguraram que leram mais de três livros, entretanto, 2 $(8,7 \%)$ não leram e $6(26,1 \%)$ não se lembram se leram e a quantidade de livros lidos. $\mathrm{Na}$ verdade, $65,2 \%$ dos alunos leem muito pouco ou não leem, o que confirma o resultado da questão 1 (EC1), na qual constata-se que exatamente $65,2 \%$ dos pesquisados não gostam de ler. $\mathrm{Na}$ EP1, a realidade constatada quanto ao número de livros lidos pelos alunos do nono ano não foi diferente, apenas $1(7,1 \%)$ aluno disse não ter lido livro, nenhum aluno registrou ter lido um

1Para

outras informações, acessar: http://plataforma.prolivro.org.br/retratos-da-leitura/ . 
livro, $2(14,3 \%)$ afirmaram ter lido dois livros, 1 $(7,1 \%)$ leu três livros, $4(28,6 \%)$ alunos afirmaram ter lido mais de três livros, e, quase a metade deles registraram que não leram, ou seja, 3 $(21,4 \%)$ ou não se lembram 3 (21,4\%) desse detalhe perguntado, totalizando $71,4 \%$ de estudantes que leem pouco ou não leem.

Dessa constatação podemos inferir que se a biblioteca escolar não é funcional, se nela não se ensina a ler e a usufruir dos benefícios de seu acervo, provavelmente há professores que não leram/leem em sua formação ou até mesmo não o fazem para ancorarem sua prática educativa.

Em relação aos aspectos "não leram ou não se lembram", Ferreira (2012), ao analisar as representações de leitura de estudantes da Educação de Jovens e Adultos (EJA), observou em sua pesquisa aspectos de esquecimento de detalhes importantes de obras lidas, por conta disso, afirma que "[...] dada a sua recorrência e familiaridade, essas representações podem se transformar em senso comum, que é uma forma de explicar a leitura de modo espontâneo" (FERREIRA, 2012, p. 62). Essa autora explica que esse detalhe poderia ser considerado como esquecimento, todavia, pela sua incidência, revela estudantes pouco familiarizados com 0 universo da leitura e com os códigos da cultura reificada.

A sexta questão respondida pelos pesquisados diz respeito à principal preferência deles quanto à leitura de livros (didático, autoajuda, ficção científica, literatura, romances ou outros). $\mathrm{Na} \mathrm{EC1}$, nenhum aluno teve preferência pelo livro didático, apenas $1(4,3 \%)$ disse que gosta de leitura de autoajuda, 8 (34,8\%) preferem livro de ficção científica, e grande parte deles 10 (43,5\%) optam por livros de literatura juvenil, mas há os que escolhem outra tipologia como: história em quadrinhos, aventura e suspense, que somam $4(17,4 \%)$ estudantes. Já na EP1, também não há procura de leitura em livros didáticos e de autoajuda. Os livros de ficção científica e os de literatura, representam, respectivamente, 4 (29\%) das escolhas. Outros como: suspense, terror, diário, mistério e gibi correspondem a $6(42,9 \%)$ das escolhas dos pesquisados.

Santos (2013), em sua investigação sobre a biblioteca escolar constatou que a relação e a função atribuída a esse espaço educacional encontra-se descaracterizado e precisa ser melhor repensado para alcançar sua funcionalidade no ambiente escolar e atingir seu objetivo fundamental que é o de contribuir com a formação de leitores, aspecto que pode colaborar com o entendimento dos estudantes das EC1 e EP1 lerem pouco. Outro aspecto que consideramos relevante nessa interpretação é o papel que os professores e a família ocupam enquanto leitores e divulgadores da importância das práticas de leitura na constituição do conhecimento.

$\mathrm{Na}$ sétima questão, foi solicitado aos alunos que numerassem ( 1 para sempre, 2 às vezes e 3 raramente), as situações em que os seus professores oportunizam atividades de leitura e estudo do material lido em sala de aula nas oito disciplinas que compõem o currículo das turmas investigadas (Arte, Ciências, Educação Física, Geografia, História, Língua Portuguesa, Língua Inglesa e Matemática). Constatamos que o trabalho pedagógico com leitura e sua compreensão se despontam na disciplina de Língua Portuguesa em ambas as escolas, o que já é tradicionalmente realizado, dada a natureza metalinguística do trabalho pedagógico nessa disciplina. Tanto na EC1 quanto na EP1, o que prevalece é que eventualmente (às vezes) são estimulados a ler. $\mathrm{Na}$ primeira escola os respondentes afirmaram que leem com mais frequência, além de Língua Portuguesa, em História, e na segunda instituição, em Geografia.

Em relação ao entendimento da escolha dos estudantes por um ou outro estilo de leitura, citamos Abric (2000, p. 27-28), ao explicar que toda representação é "[...] uma forma global e unitária de um objeto, mas também de um sujeito". Dessa forma, o autor nos leva a entender que as RS possibilitam ao indivíduo integrar as suas experiências, e nesse caso em particular, as relativas às práticas de leitura, às características do objeto, representado pelo tipo de material em que veicula significado sociocultural, atitudes e valores que atribui à atividade leitora.

Por sua vez, na oitava questão perguntamos aos estudantes a respeito dos principais passos que seus professores utilizam para a compreensão do material lido (Pesquisa em dicionário das palavras e expressões desconhecidas; Leitura silenciosa pelos alunos; Leitura oral e coletiva pelos alunos; Explicação do material lido pelo professor; Resolução de atividades de compreensão do material lido; e, considerando sua ocorrência, 1: Em todas as aulas; 2: Em quase todas as aulas; 3 : Pelo menos 
uma vez na semana; 4: Pelo menos uma vez a cada quinze dias; 5: Raramente; 6: Nunca realiza a atividade). Na EC1, 14 (60,9\%) dos alunos não consultam em dicionário; 11 (47,8\%) mencionaram realizar leitura silenciosa; 19 $(82,6 \%)$ realizam leitura oral e coletiva; 8 (34,8\%) dos professores explicam o material lido. Na EP1, 7 (50\%) dos pesquisados não consultam em dicionário; 7 (50\%) realizam leitura silenciosa; $7(50 \%)$ afirmou não ser prioridade aula de leitura oral; 12 (52,2\%) sugerem eventualidade de explicação pelo professor do material e 3 (13\%) negaram tal prática em aula.

Ferreira (2012) em sua investigação de mestrado constatou que as RS dos estudantes participantes de sua pesquisa, revelam que na escola, quase sempre, a leitura é uma atividade de decodificação, e em consequência dessa prática metodológica, essa instituição não tem cumprido com a sua função de formar sujeitos leitores fluentes. Em consonância com os achados de Ferreira (2012), Duarte (2012) concluiu que os docentes de sua pesquisa representam a necessidade de aprofundamento de estudos sobre estratégias de leitura em sala de aula na formação docente.

Ainda que os pesquisados estejam cientes dessa realidade pedagógica no estudo do texto, as atividades envolvendo leitura e escrita nas diferentes disciplinas escolares, quase sempre, não contemplam um estudo que leve o aluno a ler e a escrever como aporte para apreender os conhecimentos científicos de suas respectivas áreas de saber, no processo de construção de sua autonomia linguística.

Asseguramos que adequadas estratégias de ensino são coadjuvantes no processo de compreensão do conteúdo estudado, em qualquer área do conhecimento, pois a organização mental dos passos para a interpretação de um texto está na dependência dos processos de decodificação, compreensão, interpretação e retenção (MENEGASSI, 1995).

Concordamos com a afirmativa anterior sobre a sequência cognitiva que envolve o ato da leitura, entretanto, ensinar o estudante a ler e interpretar o material lido demanda o domínio dos passos apresentados, bem como diferenciálos em suas diferentes etapas, embora sejam processos não lineares, portanto interligados. Para isso, um dos principais aspectos a se considerar é que todos os professores compreendam como tal processo acontece, e de que forma pode interferir/mediar o aprendizado e desenvolvimento da capacidade leitora de seu aluno.

Na nona e última questão referente às práticas de leitura dos estudantes pesquisados, foram indagados a respeito dos principais tipos de leitura realizadas em sala de aula (Leitura silenciosa pelo aluno; Leitura oral pelos alunos; Leitura silenciosa e oral pelos alunos; Leitura silenciosa e oral pelos alunos e professor). $\mathrm{Na}$ EC1,6 (26,1\%) dos estudantes realizam leitura oral em sala de aula; $5(21,7 \%)$ referiram que as atividades de leitura realizadas por eles são silenciosas e orais; e, 12 (52,2\%) afirmaram que estas atividades são realizadas por eles e seus professores. $\mathrm{Na}$ EP1, 7 (50\%) deles realizam leitura silenciosa em sala de aula; 1 (7\%) realiza leitura oral; 6 (42,9\%) assinalaram que realizam leitura oral e silenciosa tanto por eles quanto por seus professores.

De modo geral, as RS dos estudantes dos nonos anos pesquisados sobre leitura nos revelam que eles leem muito pouco, assim como a representação que têm de seus colegas de sala, e centram em si a responsabilidade pela ausência dessa prática. Quanto ao tipo de livro que mais gostam de ler, citaram os de ficção científica e de literatura infanto-juvenil, este possivelmente por ser indicado pela escola. Já no que se refere ao tipo de material de leitura, foram enfáticos ao preferirem a forma veiculada pelas tecnologias digitais. Entretanto, é plausível inferirmos que essa prática, principalmente as decorrentes das redes sociais, não passa de poucas palavras e de duas ou três frases, no máximo, por ser eminentemente contextualizada. Não queremos com essa colocação desconsiderarmos esse momento histórico de interações sociais, mas que dependendo do contexto, como a escola, a escrita se realiza em outros moldes, com características próprias e cientificamente exigidas. Os poucos estudantes que afirmaram gostar de ler em materiais impressos, nos deram pistas para deduzirmos que são os referidos por seus professores enquanto leitores assíduos.

Enfim, as RS dos estudantes desta pesquisa os situam como não leitores, que leem quase que exclusivamente para cumprir obrigações escolares, geralmente são atividades metalinguísticas com poucas inferências e pouco saber criativo. Os escassos alunos que leem com assiduidade o fazem por compreenderem a função social da leitura. No entanto, acreditam que seus colegas de turma, em sua maioria, não apresentam prática leitora. A constatação de que 
os estudantes das escolas públicas pouco leem não é novidade para gestores, equipe pedagógica e professores, no entanto, as RS deles sobre essa atividade linguística, fornecem pistas profícuas para se (re) pensar a formação inicial e continuada de professores, a relação família e escola e, sobretudo, a necessidade de práticas pedagógicas interdisciplinares em que a leitura alcance suas funções sociais, afetivas, formativas e outras.

Na sequência, apresentamos o Quadro 2 no qual sintetizamos os dados de nossa pesquisa de campo sobre RS dos estudantes dos nonos anos pesquisados a respeito do ensinoaprendizagem interdisciplinar da escrita.

\section{REPRESENTAÇÕES SOCIAIS SOBRE ENSINO- APRENDIZAGEM DA ESCRITA}

O Quadro 2 é composto à esquerda por RS de 23 (vinte e três) estudantes da EC1, e à direita é constituído pelas RS de 14 (quatorze) alunos da EP1, correspondente à segunda parte do questionário instrumento da presente pesquisa com 9 (nove) questões referentes ao ensino-aprendizagem da escrita, interpretadas de forma estatística e qualitativa.

Quadro 2. Dados percentuais das Representações Sociais de estudantes do nono ano sobre escrita

\begin{tabular}{|c|c|c|c|c|c|}
\hline \multicolumn{6}{|c|}{ REPRESENTAÇÕES SOCIAIS DE ESTUDANTES DO NONO ANO SOBRE LEITURA } \\
\hline \multicolumn{3}{|c|}{ EC1 -23 estudantes } & \multicolumn{3}{|c|}{ EP1 -14 estudantes } \\
\hline №. & Questionamentos & Respostas & №. & Questionamentos & Respostas \\
\hline 01 & Gosto pela leitura & $\begin{array}{l}8(34,8 \%) \text { gostam de ler; } 2(8,7 \%) \\
\text { não gostam; } 13(56,5 \%) \text { às vezes; } \\
15(65,2 \%) \text { não gostam ou não } \\
\text { têm hábito à leitura. }\end{array}$ & 01 & Gosto pela leitura & $\begin{array}{l}2(14,3 \%) \text { gostam de ler; } 4(28,6 \%) \text { não } \\
\text { gostam; } 8 \text { ( } 57,1 \%) \text { leem às vezes; } 12 \\
(85,7 \%) \text { não gostam ou não têm } \\
\text { hábito à leitura. }\end{array}$ \\
\hline 02 & $\begin{array}{l}\text { Tipo de material } \\
\text { preferem ler }\end{array}$ & $\begin{array}{l}7(30,4 \%) \text { preferem ler em } \\
\text { material impresso; } 16 \quad(69,6 \%) \\
\text { preferem ler em materiais } \\
\text { digitais. }\end{array}$ & 02 & $\begin{array}{l}\text { Tipo de material } \\
\text { preferem ler }\end{array}$ & $\begin{array}{l}3(21,4 \%) \text { para as formas tradicionais } \\
\text { de leitura; } \mathbf{1 1}(\mathbf{7 8 , 6 \% )} \text { preferem ler em } \\
\text { material impresso. }\end{array}$ \\
\hline 03 & $\begin{array}{l}\text { RS sobre leitura } \\
\text { extraescolar dos } \\
\text { colegas de classe }\end{array}$ & $\begin{array}{l}\text { Nenhum aluno afirmou que seus } \\
\text { colegas leem sempre; } 7(30,4 \%) \\
\text { leem às vezes; } 13(56,5 \%) \text { leem } \\
\text { raramente; } 3 \text { (13\%) acreditam } \\
\text { que os colegas não leem; ou } \\
\text { seja, } 16 \text { (69,5\%) representam } \\
\text { que os colegas não leem fora da } \\
\text { escola. }\end{array}$ & 03 & $\begin{array}{l}\text { RS sobre leitura } \\
\text { extraescolar dos colegas } \\
\text { de classe }\end{array}$ & $\begin{array}{l}1 \text { (7,1\%) de seus colegas leem sempre } \\
\text { ou de vez em quando; } 10 \text { (71,4\%) } \\
\text { raramente leem; } 2 \text { (14,3\%) não o } \\
\text { fazem fora da escola. Estas } \\
\text { informações dão conta que } \mathbf{1 2}(\mathbf{8 5 , 7 \% )} \\
\text { desconsideram a importância dos } \\
\text { hábitos de estudo extraescolares. }\end{array}$ \\
\hline 04 & $\begin{array}{l}\text { Motivos pelos quais os } \\
\text { colegas de classe leem } \\
\text { pouco }\end{array}$ & $\begin{array}{l}2(8,7 \%) \text { reconhecem que não } \\
\text { são ensinados e motivados ou } \\
\text { não têm acesso a materiais de } \\
\text { leitura; } \mathbf{2 1} \quad(\mathbf{9 1 , 3 \% )} \text { são } \\
\text { responsáveis por não gostar de } \\
\text { ler. }\end{array}$ & 04 & $\begin{array}{l}\text { Motivos pelos quais os } \\
\text { colegas de classe leem } \\
\text { pouco }\end{array}$ & 14 (100\%) não gostam de ler. \\
\hline 05 & $\begin{array}{l}\text { Quantidade de livros } \\
\text { lidos nos últimos dois } \\
\text { anos }\end{array}$ & $\begin{array}{l}3(13 \%) \text { não leram; } 2(8,7 \%) \text { leu } \\
\text { um livro; nenhum aluno leu dois } \\
\text { livros; } 2(8,7 \%) \text { leram três livros; } \\
8(34,8 \%) \text { leram mais de três } \\
\text { livros; } 2(8,7 \%) \text { não leram; } 6 \\
(26,1 \%) \text { não se lembram; ou } \\
\text { seja, } 65,2 \% \text { dos alunos leem } \\
\text { muito pouco ou não leem. }\end{array}$ & 05 & $\begin{array}{l}\text { Quantidade de livros } \\
\text { lidos nos últimos dois } \\
\text { anos }\end{array}$ & $\begin{array}{l}1(7,1 \%) \text { não leu; } 2(14,3 \%) \text { leram dois } \\
\text { livros; } 1 \text { (7,1\%) leu três livros; } 4 \\
(28,6 \%) \text { leram mais de três livros; } 3 \\
(21,4 \%) \text { não leram; } 3(21,4 \%) \text { não se } \\
\text { lembram, totalizando } 71,4 \% \text { de } \\
\text { estudantes que leem pouco ou não } \\
\text { leem. }\end{array}$ \\
\hline 06 & $\begin{array}{l}\text { Tipos de livros } \\
\text { preferem ler }\end{array}$ & $\begin{array}{l}\text { Nenhum aluno prefere o livro } \\
\text { didático; } 1 \text { (4,3\%) gosta } \\
\text { autoajuda; } 8(34,8 \%) \text { escolhem } \\
\text { ficção científica; } 10 \text { (43,5\%) } \\
\text { optam por livros de literatura } \\
\text { juvenil; } 4(17,4 \%) \text { escolhem } \\
\text { outra tipologia como: história } \\
\text { em quadrinhos, aventura e } \\
\text { suspense. }\end{array}$ & 06 & $\begin{array}{l}\text { Tipos de livros preferem } \\
\text { ler }\end{array}$ & 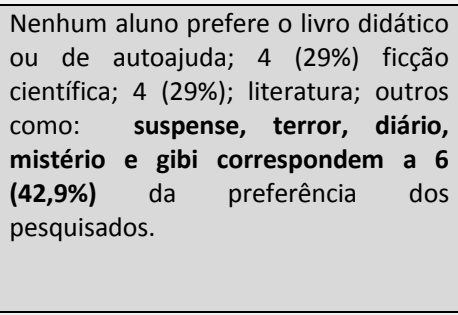 \\
\hline 07 & $\begin{array}{l}\text { Disciplinas que } \\
\text { trabalham } \\
\text { sistematicamente com } \\
\text { leitura em sala de aula }\end{array}$ & $\begin{array}{l}\text { Trabalho constante com leitura: } \\
\text { Arte } 6 \quad(26,1 \%) ; \text { Ciências } 6 \\
(26,1 \%) ; \text { Educação Física } 2(8,7) ; \\
\text { Geografia } 6(26,1 \%) ; \text { História } 15 \\
(65,2 \%) ; \quad \text { Língua Inglesa } 9 \\
(39,1 \%) ; \text { Língua Portuguesa; } 18 \\
(78,3 \%) ; \text { e, matemática 3 (13\%). }\end{array}$ & 07 & $\begin{array}{l}\text { Disciplinas que } \\
\text { trabalham } \\
\text { sistematicamente com } \\
\text { leitura em sala de aula }\end{array}$ & $\begin{array}{l}\text { Trabalho constante com leitura: Arte } \\
3 \quad(21,4 \%) ; \quad \text { Ciências } 5 \quad(35,7 \%) ; \\
\text { Educação Física } 3(21,4) ; \text { Geografia } 6 \\
(42,9 \%) ; \text { História } 4 \quad(28,6 \%) ; \text { Língua } \\
\text { Inglesa } 4(28,6 \%) ; \text { Língua Portuguesa } \\
11(78,6 \%) ; \text { e, matemática } 4(28,6 \%) \text {. }\end{array}$ \\
\hline 08 & $\begin{array}{l}\text { Principais passos e } \\
\text { frequência no estudo } \\
\text { do material lido em } \\
\text { aula }\end{array}$ & $\begin{array}{l}14(60,9 \%) \text { não consultam em } \\
\text { dicionário; } 11(47,8 \%) \text { realizam } \\
\text { leitura silenciosa; } 19 \quad(82,6 \%) \\
\text { realizam leitura oral e coletiva; } 8\end{array}$ & 08 & $\begin{array}{l}\text { Principais passos e } \\
\text { frequência no estudo do } \\
\text { material lido em aula }\end{array}$ & 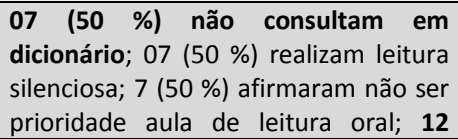 \\
\hline
\end{tabular}




\begin{tabular}{|c|c|c|c|c|c|}
\hline & & $\begin{array}{l}(34,8 \%) \text { dos professores } \\
\text { explicam o material lido. }\end{array}$ & & & $\begin{array}{l}(52,2 \%) \text { sugerem eventualidade de } \\
\text { explicação pelo professor do } \\
\text { material; } 3(13 \%) \text { negaram tal prática. }\end{array}$ \\
\hline 09 & $\begin{array}{l}\text { Principais práticas de } \\
\text { leitura em sala de aula }\end{array}$ & $\begin{array}{l}6(26,1 \%) \text { realizam leitura oral } \\
\text { em sala de aula; } 5(21,7 \%) \\
\text { referiram que as atividades de } \\
\text { leitura realizadas por eles são } \\
\text { silenciosas e orais; } 12 \text { (52,2\%) } \\
\text { que estas atividades são } \\
\text { realizadas por eles e por seus } \\
\text { professores. }\end{array}$ & 09 & $\begin{array}{l}\text { Principais práticas de } \\
\text { leitura em sala de aula }\end{array}$ & $\begin{array}{l}7(50 \%) \text { realizam leitura oral em sala } \\
\text { de aula; } 1(7 \%) \text { realiza leitura oral; } 6 \\
(42,9 \%) \text { assinalaram que realizam } \\
\text { leitura oral e silenciosa tanto por eles } \\
\text { quanto por seus professores. }\end{array}$ \\
\hline
\end{tabular}

Fonte: Os autores.

Nota: Pesquisa de campo própria.

A primeira questão dirigida aos estudantes foi sobre o gosto que têm pelas atividades de escrita. Dos pesquisados da EC1, 6 $(26,1 \%)$ afirmaram que gostam de escrever, 2 $(8,7 \%)$ asseguraram que não apreciam tal atividade, e a grande maioria, 15 (65,2\%) manifestaram que às vezes gostam de escrever. Dos alunos da EP1, 8 (57,1\%) declararam afinidade com a escrita, $1(7,1 \%)$ negou gostar de escrever, e $5(35,7 \%)$ revelaram que há oportunidades em que gostam de desenvolver tal atividade. Esses dados confirmam o que a literatura da área demonstra, bem como os resultados das avaliações externas. Em contrapartida, trata-se de uma atividade simbólica organizada por meio de signos linguísticos com regras de funcionamento diferentes da estrutura da fala, que exige alto grau de abstração e uma forte e deliberada análise consciente em seu processo de produção (VIGOTSKI, 2000), o que pode ter contribuído com as representações dos participantes da pesquisa sobre não gostarem de escrever, ou por realizarem atividades dessa natureza e não compreenderem a sua finalidade. Outro aspecto a ser considerado diz respeito à finalidade com que é trabalhada na escola, uma vez que se ela, quase sempre, não atende a sua função social, torna-se assim uma atividade descontextualizada e mecânica, puramente utilizada para fins metalinguísticos.

A segunda questão diz respeito à forma como os pesquisados avaliam a sua escrita, se boa, ótima ou regular. Dos 23 alunos da EC1, 10 $(43,5 \%)$ dos estudantes a consideram boa, ou seja, provavelmente ao escreverem não se deparam com questões relativas a dúvidas frequentes, insegurança ou traumas com esta atividade de representação simbólica e materialização de suas ideias. Contudo, um número reduzido $2(8,7 \%)$ dos participantes considera que sua escrita pode ser avaliada como ótima, e em maior percentagem, 11 (47,8\%) deles não a avaliam como satisfatória. Entre os conceitos boa e ótima, somam-se 12 (52,2\%) das respostas. A autoavaliação da escrita dos alunos da EP1 sinaliza que 2 (14,3\%) deles referem facilidade na escrita, e $1(7,1 \%)$ a considera ótima, entretanto $11(78,6 \%)$ tem consciência de seus limites e dificuldades ao escrever. Ao avaliar a própria escrita, o estudante considera outras representações dela, principalmente, das atividades escolares avaliadas por seus professores, colegas de turma e algumas vezes por seus pais. $\mathrm{E}$ ao representar-se ou representar algo ou alguma noção, o sujeito, a partir de uma coletividade representada em si, ocupa um lugar social para significar a realidade ou a condição em que se encontra, e, nesse processo "[...] não produzimos unicamente nossas ideias e imagens: criamos e transmitimos um produto progressivamente elaborado em inúmeros lugares, segundo regras variadas" (MOSCOVICl, 2001, p. 63). Isto é, ao avaliar-se e avaliar a escrita dos colegas de sala, os estudantes se ancoram em seu grau de experiência ao se expressar por meio de um texto, bem como em suas dificuldades ou facilidades ao objetivá-lo.

Em terceiro lugar, foi perguntado aos participantes se o ensino da leitura e escrita deveria ser responsabilidade exclusivamente do/a professor/a da disciplina de Língua Portuguesa ou se de todos os seus professores. Nos dados da EC1, grande parte dos alunos 19 $(82,6 \%)$ têm consciência de que o trabalho de estudo sistemático com a Língua Portuguesa não é somente atribuição do/a professor/a desta disciplina, portanto, ainda $4(17,4 \%)$ representam que esta incumbência é restrita a esse/a profissional. Para os estudantes da EP1, a situação se apresenta mais agravante, uma vez que $8(57,1 \%)$ consideram ser uma atividade de ensino exclusiva do/a professor/a de Língua Portuguesa contra 6 (42,9\%) deles que afirmam ser responsabilidade de todos os seus professores. Essa tomada de posição ao 
representar quem deve ou não trabalhar sistematicamente com a leitura e escrita, nos remete ao entendimento de Doise (2001, p. 193) ao afirmar que "[...] as representações sociais são sempre tomadas de posição simbólicas, organizadas de maneiras diferentes". Com base nesse posicionamento podemos inferir que as RS dos estudantes apontam que o domínio da leitura e escrita não é percebida como condição básica para se apreender os conteúdos curriculares de todas as disciplinas escolares. Essa dedução pode ser decorrente de estratégias de ensino veiculadas pela língua materna pouco motivadoras, como responder questionários rotineiramente.

A quarta questão dirigida aos estudantes foi a respeito da atividade da escrita, se na opinião deles, é fácil, difícil ou muito difícil. De acordo com os resultados da EC1, 17 (73,9\%) dos examinados referem ser a escrita uma atividade fácil, $4(17,4 \%)$ a considera difícil e $2(8,7 \%)$ deles a tem como uma atividade muito difícil. Fato semelhante ocorreu na EP1, no qual $12(85,7 \%)$ assinalou a escrita como sendo fácil, e apenas 2 $(14,3 \%)$ a considera como difícil, e não houve registros de ser muito difícil. Para consubstanciar essa constatação, localizamos na pesquisa de mestrado de Ferreira (2013) as representações discentes da EJA sobre a escrita, ora tida como "aflição" sobre o quê e de que maneira escrever e, ao mesmo tempo, referida como "luta", ao enfrentarem as dúvidas decorrentes dessa atividade considerada altamente complexa e abstrata. Assim sendo, precisamos refletir sobre as ancoragens que os alunos investigados denotam ao se referirem como (não)leitores e (não)escritores e as implicações que essas representações têm em seu desenvolvimento acadêmico. Uma ação motivadora de leitura e escrita é a análise pelo coletivo da escola sobre o papel que a biblioteca escolar ocupa no desenvolvimento linguístico do aluno, aspecto que precisa estar atrelado ao Projeto Pedagógico da escola, bem como orientar como o trabalho pedagógico multidisciplinar deve contemplar essa necessidade dos estudantes e professores das várias áreas do conhecimento.

A quinta interrogação foi quanto às atitudes dos pesquisados ao se depararem com uma dúvida ao escrever uma palavra ou para registrar uma ideia, se diante disso: solicita ajuda ao professor ou a um colega de turma, se consulta no livro didático ou se permanece com a dúvida. Dos respondentes, $6(26,1 \%)$ da turma da
EC1 refere solicitar ao professor explicação sobre suas dúvidas, ao passo que $14(60,9 \%)$ interagem com os colegas de classe, solicitando-lhes ajuda, e apenas $1(4,3 \%)$ deles recorre ao livro didático para resolvê-las, entretanto, um número considerável, pela gravidade da questão, 2 $(8,7 \%)$ prefere ficar em silêncio, permanecendo com a dúvida. De forma semelhante, os alunos da EP1 responderam que $4(28,6 \%)$ deles solicitam explicações ao professor, 7 (50\%) também recorrem aos colegas de turma, $2(14,3 \%)$ apelam ao livro didático e $1(7,1 \%)$ não toma atitude em relação à dúvida de escrita. Essa resposta aponta para a necessidade de os professores organizarem o grupo de alunos para trabalhos com interações, discussões e reflexões, haja vista que a dependência social é inerente à condição humana, e, colocar os estudantes em situação de poder exercer sua fala, levantar hipóteses, de ser confrontados e elaborar conclusões, ajuda-os a sentirem-se partícipes do processo de aprendizagem. Assim sendo, estratégias diversificadas de ensino contribuem com as especificidades de aprendizagem considerando o individual e o coletivo sintetizados no social de sala de aula.

Na sexta posição de investigação sobre a escrita, buscamos identificar em quais das oito disciplinas os professores dos investigados trabalham com a produção escrita e a sua correção, em sala de aula, considerando (1 para sempre, 2 às vezes e 3 raramente), em Arte, Ciências, Educação Física, Geografia, História, Língua Portuguesa, Língua Inglesa e Matemática. De forma análoga às questões de leitura, constatamos que o trabalho pedagógico com a produção escrita se desponta na disciplina de Língua Portuguesa em ambas as escolas, o que já é tradicionalmente realizado, dada a natureza metalinguística do trabalho pedagógico nessa disciplina. Tanto na EC1 quanto na EP1, o que prevalece é que eventualmente (às vezes) são estimulados a escrever, entretanto essa prática acontece com mais frequência na EC1 nas disciplinas de Línguas Portuguesa e Inglesa. Em conformidade com o que a literatura demonstra, quase sempre as atividades de escrita ficam sob a responsabilidade das aulas de Língua Portuguesa, entretanto, ensinar a escrever, escrevendo textos com sentido e significado social é um dos grandes desafios da escola contemporânea, e é uma necessidade generalizada de todas as áreas do conhecimento (GUEDES; SOUZA, 2011). Em decorrência dessa afirmação, bem como da 
constatação da presente pesquisa, a formação continuada de professores deve contemplar, em todas as áreas curriculares, o estudo de como o texto (conteúdo veiculado pela língua materna) precisa ser trabalhado pedagogicamente.

A sétima indagação feita aos pesquisados diz respeito às principais dúvidas que possuem em relação à escrita (ortográficas, gramaticais ou textuais). Os dados mostram que $8(34,8 \%)$ dos estudantes da EC1 referiram suas principais dificuldades as relativas à ortografia das palavras, enquanto $11(47,8 \%)$ registraram que estas são de ordem gramatical e $4(17,4 \%)$ afirmaram ser as de organização e progressão textual. Os participantes da EP1 representaram suas principais dúvidas em ortografia, sinalizadas por 6 $(42,9 \%)$ deles, e $4(28,6 \%)$ as dificuldades gramaticais e de igual percentual as relativas à produção textual, com $4(28,6 \%)$ da turma. A esse respeito, destacam Zuin e Reyes (2010), que os estudos linguísticos sob a perspectiva vigotskiana e bakhtiniana, enfatizam a importância do caráter semântico na realização do discurso ao levar os sujeitos a se constituírem na e pela linguagem. Corroborando com essa ideia, Travaglia (2011, p. 41) sustenta que "[...] a gramática de uma língua é o conjunto de condições linguísticas para a significação. [...] tudo o que é textual é gramatical”. Ou seja, os recursos gramaticais são utilizados na composição de um texto atribuindo-lhe sentidos, o que possibilita a interação comunicativa.

$\mathrm{Na}$ penúltima questão, os pesquisados enumeraram por ordem de prioridade a ocorrência de atividades de escrita: Questionário com perguntas e respostas; Elaboração de resumos e resenhas dos conteúdos dos livros didáticos; Produção de textos; Apontamentos das principais ideias do texto; Completar mapas, considerando 1: Em todas as aulas; 2: Em quase todas as aulas; 3: Pelo menos uma vez na semana; 4: Pelo menos uma vez a cada quinze dias; 5: Raramente; 6: Nunca realiza a atividade. As atividades referidas pelos alunos da EC1 que são mais frequentemente realizadas são: 15 $(65,2 \%)$ questionário com perguntas e respostas; 6 (26,1\%) produção de texto; e, 6 (26,1\%) apontamentos das principais ideias do texto. Enquanto para os pesquisados da EP1 são: 8 $(57,1 \%)$ questionário com perguntas e respostas; $5(35,7 \%)$ elaboração de resumos e resenhas; 4 $(28,6 \%)$ produção de textos. Os dados mostram que os professores utilizam predominantemente questionário com perguntas e respostas em suas aulas, no entanto, além da importância da compreensão do funcionamento sígnico ao se trabalhar com a língua materna, outra questão que precisa ficar bem marcada no ensino dos conteúdos em geral é a de que nas várias disciplinas circulam diferentes gêneros textuais (propagados socialmente também), e o trabalho escolar sistemático, a partir do contexto em que veiculam, pode contribuir com o desenvolvimento linguístico do estudante.

Com propósito de melhor entendermos - problema exposto, recorremos aos pressupostos bakhtinianos e vigotskianos, aproximando-os do atual contexto educacional, sob o qual é preciso atentar para o caráter de mediação que os docentes exercem entre o aluno e o objeto de conhecimento, perpassados pelo signo, e em nosso objeto de pesquisa, o sistema de representação linguístico e as várias formas em que ele se manifesta. Para Bakhtin/Volochínov (2014), os signos em geral apresentam um caráter ideológico, enquanto para Vigotski (2000), estes desempenham funções imprescindíveis no sistema psíquico humano. A partir desse entendimento, depreendemos que esses teóricos ressaltam a importância da mediação sígnica (ZUIN; REYES, 2010).

Além da importância da compreensão do funcionamento sígnico, outra questão que precisa ficar bem marcada no ensino dos conteúdos em geral é a de que nas várias disciplinas circulam diferentes gêneros textuais (propagados socialmente também), e o trabalho escolar sistemático, a partir do contexto em que veiculam, pode contribuir com o desenvolvimento linguístico do estudante.

Fonseca (2015), em sua tese de doutorado, examinou e discutiu o agir metodológico de uma professora de Língua Portuguesa e constatou que o espaço de sua aula funciona como um gênero discursivo. Acreditamos que esse modelo didático pode ser utilizado/representado em várias áreas do conhecimento, pois como exemplo, um conteúdo de Arte apresenta uma dimensão política, filosófica, geográfica, histórica, econômica, social, cultural e outras que compreendem a sua totalidade (GASPARIN, 2002).

A nona e última questão respondida em nossa pesquisa pelos estudantes do nono ano sobre escrita foi a respeito da atribuição de uma nota de zero a dez ao trabalho pedagógico que o conjunto de seus professores realiza em leitura e 
escrita, para o aprendizado dos conteúdos escolares, conforme os conceitos, entre 0 e 3: 0 trabalho pedagógico em leitura e escrita é insatisfatório; entre 4 e 5: o trabalho pedagógico em leitura e escrita é regular; entre 6 e 8: o trabalho pedagógico em leitura e escrita é bom; entre 9 e 10: o trabalho pedagógico em leitura e escrita é muito bom. A avaliação dos alunos da turma da EC1, do trabalho pedagógico desenvolvido por seus professores envolvendo atividades de leitura e escrita, mostra que 1 $(4,3 \%)$ o refere como insatisfatório, $5(21,7 \%)$ como sendo regular, $16(69,5 \%)$ declarou ser bom e $1(4,3 \%)$ o teve como muito bom. Os dados coletados na EP1 são parecidos, no qual nenhum pesquisado avaliou o trabalho de seus docentes como insatisfatórios, 1 (7,1\%) diz ser um trabalho regular, $12(85,7 \%)$ apresentam o conceito de bom trabalho pedagógico e $1(7,1 \%)$ refere como sendo muito bom. Os resultados mostram que os alunos avaliam como satisfatório o trabalho pedagógico desenvolvido por seus professores, mas apenas um aluno de cada escola o vê como ótimo ou excelente. Essa apreciação nos remete à ideia de que "Categorizar alguém ou alguma coisa significa escolher um dos paradigmas estocados em nossa memória e estabelecer uma relação positiva ou negativa com ele" (MOSCOVICl, 2015, p. 63).

De forma geral, a síntese dessas representações sinaliza que: os pesquisados não gostam ou não têm hábito à leitura; preferem ler em materiais digitais; não têm hábito de estudo fora da escola; representam que são os responsáveis por não gostarem de ler; a grande maioria dos alunos leem poucos livros, ou seja, da EC1 $65,2 \%$ e da EP1 71,4\% referiram ler muito pouco; nenhum aluno referiu gostar de ler o livro didático, um número considerável da EC1 10 $(43,5 \%)$ opta por livros de literatura juvenil e boa parte da EP1 elegeu suspense, terror, diário, mistério e gibi, o que corresponde a $6(42,9 \%)$ da preferência dos pesquisados; sobre as disciplinas que trabalham sistematicamente com leitura em sala de aula, as de Língua Portuguesa, História e Geografia foram as mais citadas; no que se refere aos principais passos e frequência no estudo do material lido em aula, há insuficiente estudo e explicação do texto estudado; a atividade de leitura oral por alunos e professores versa em torno de $50 \%$ das aulas de leitura.

No que se refere às práticas de escrita, as representações dos educandos pesquisados são também reveladoras de que os seus professores, apesar de fazerem uso de estratégias diferentes para se trabalhar os conteúdos das várias disciplinas escolares, por meio de práticas de leitura e escrita, essas são, muitas vezes, mecânicas, descontextualizadas e insuficientes e, como exemplo, ao se trabalhar o texto (entendido em seus vários gêneros), representam que é uma prática pouco frequente, e ainda assim, serve como forma de correção para atribuição de nota, ao contrário da avaliação processual, que nela, se observa as transgressões, mas também os acertos, para prosseguimento da formação dos estudantes. Ao se representarem nas atividades de escrita, houve um contrassenso, pois ao mesmo tempo em que afirmaram ser a escrita uma atividade de fácil realização, grande parte dos respondentes disseram não gostar de escrever, fato que nos leva a refletir sobre a função social da escrita trabalhada na e pela escola, que é, muitas vezes, negligenciada, como quando observamos em uma das aulas, atividades de formar frases, e, contrapondo essa estratégia para as vivências e exigências socioculturais, nos perguntamos: em qual/quais situações essas atividades são postas pela prática social dos estudantes?

Enfim, ler e compreender o material lido e objetivar o pensamento por meio do registro escrito são habilidades linguísticas trabalhadas na Educação Básica, mas como vimos nas RS dos estudantes do último ano do Ensino Fundamental (nonos anos), com nove anos letivos de estudo da língua constatamos muitas lacunas, principalmente as concernentes ao trabalho interdisciplinar em leitura e escrita das várias disciplinas que compõem o currículo desse ano escolar.

\section{CONSIDERAÇÕES FINAIS}

O presente artigo apresentou as RS de estudantes de duas turmas do nono ano do Ensino Fundamental sobre 0 ensinoaprendizagem da leitura e escrita. Essas representações são bastante preocupantes, pois não destoam dos resultados que os exames externos demonstram, bem como da própria realidade vivida no dia a dia escolar, na qual um número significativo de alunos são aprovados por conselho de classe, o que indica que nem todos se apropriaram dos conteúdos mínimos para frequentar o ano/série subsequente.

Por outro lado, ouvir e analisar o que os estudantes têm a dizer sobre como aprendem, o que gostam de ler, em que instrumento, com 
qual frequência, como é a sua escrita, quais são suas principais dúvidas ao escrever, como seus professores ensinam essas atividades linguísticas, se todos os docentes têm a preocupação de trabalhar sistematicamente com a língua materna ou se somente o/a professor/a de Língua Portuguesa, são alguns dos aspectos que buscamos investigar.

Em suma, as representações dos estudantes desta pesquisa os situam como não leitores e não produtores de textos coesos e coerentes, que leem e escrevem quase que exclusivamente para cumprir obrigações escolares, geralmente são atividades metalinguísticas com poucas inferências e pouco saber criativo. Os escassos alunos que apresentam práticas de leitura e escrita com assiduidade o fazem por compreenderem a função social dessas habilidades linguísticas. No entanto, acreditam que seus colegas de turma, em sua maioria, não apresenta tal prática. Trazendo esse entendimento para a nossa investigação, as RS dos estudantes objetivam o que eles vivenciam, percebem e concebem do ensino-aprendizagem da leitura e escrita em todas as disciplinas que compõem o currículo dos nonos anos.

Aspectos esses que precisam ser considerados pelo coletivo da escola e discutidos em reuniões de professores, nos conselhos escolares, nas formações continuadas, nos momentos de planejamento, enfim, os estudantes sinalizam como se situam nesse universo decadente da leitura e escrita e essas RS precisam ser ouvidas, refletidas e tomadas como pressupostos de mudança e superação dessa realidade de ensino-aprendizagem dessas habilidades linguísticas.

Além disso, reflexões precisam ser dirigidas sobre o currículo de formação do professor da Educação Básica. Acreditamos que a disciplina de Língua Portuguesa ou Linguística do Ensino da Língua Portuguesa devam perpassar os vários anos dos cursos de graduação que formam professores. Ainda sobre esse quesito, o professor desse segmento de ensino precisa estar instrumentalizado a respeito das práticas direcionadas de leitura e escrita como promotoras do desenvolvimento linguístico do estudante, sejam em suas dimensões históricas, geográficas, artísticas, filosóficas, conceituais e tantas outras que formam a totalidade do conhecimento presente em um determinado conteúdo ensinado pela escola.
As constatações que temos com a presente pesquisa não se esgotam aqui, portanto outras que buscam investigar as RS de estudantes na relação ensino-aprendizagem são sempre necessárias para sustentar tomadas de decisões a respeito da realidade educacional brasileira.

\section{REFERÊNCIAS}

ABRIC, J. C. A abordagem estrutural das representações sociais. In: MOREIRA, A. S. P.; OLIVEIRA, D. C. Estudos interdisciplinares de representações sociais. Goiânia: $A B, 2000$. p. 2738.

BAKHTIN, M. M.; VOLOCHÍNOV, V. N. Marxismo e filosofia da linguagem. 16. ed. São Paulo: Hucitec, 2014.

DOISE, W. Atitudes e representações sociais. In: JODELET, D. As representações sociais. (Org.). Rio de Janeiro: EDUERJ. 2001. p. 187-203.

DUARTE, M. R. Representações sociais dos professores de Língua Portuguesa sobre estratégias/práticas de leitura em sala de aula no ensino médio. 2012. 154 f. Dissertação (Mestrado em Educação) - Universidade Católica de Santos, Santos, 2012.

FERREIRA, S. M. Escrita: representações sociais de discentes na EJA do IFF campus Campos Centro. 2013. 101 f. Dissertação (Mestrado em Cognição e Linguagem) - Universidade Estadual do Norte Fluminense Darcy Ribeiro, Centro de Ciências do Homem, Campo dos Goytacazes, 2013.

FERREIRA, V. S. A. A leitura na educação de jovens e adultos: experiências e representações. 2012. 113 f. Dissertação (Mestrado em Estudos da Linguagem) - Universidade do Estado da Bahia, Salvador, 2012.

FONSECA, J. Z. B. Aula de Língua Portuguesa: representações e identidade no agir docente. 2015. $184 \mathrm{f}$. Tese (Doutorado em Letras) Pontifícia Universidade Católica de Minas Gerais, Programa de Pós-Graduação em Letras, Belo Horizonte, MG, 2015.

GASPARIN, J. L. Uma Didática para a Pedagogia Histórico-Crítica. 3. ed. Campinas, SP: Autores Associados, 2002. 
GUEDES, P. C.; SOUZA, J. M. de. Não apenas o texto, mas o diálogo em língua escrita e o conteúdo da aula de português. In: NEVES, I. C. B.et al.Ler e escrever: compromisso de todas as áreas. 9. ed. Porto Alegre: Editora da UFRS, 2011. p. 141-160.

MATENCIO, M. L. M. Formação do professor e representações sociais de língua(gem): por uma lingüística implicada. Filol. lingüíst. port., São Paulo, n. 8, p. 439-449, 2006. Disponível em: http://www.revistas.usp.br/flp/article/view/5976 5. Acesso em: 10 dez. 2020. DOI: 10.11606/issn.2176-9419.v0i8p439-449

MENEGASSI, R. J. Compreensão e interpretação no processo de leitura: noções básicas ao professor. Revista Unimar, Maringá, v. 17, n. 1, p. 85-94, 1995.

MOSCOVICI, S. A representação social da psicanálise. Rio de Janeiro, RJ: Zahar Editores, 1978.

MOSCOVICI, S. Das representações coletivas às representações sociais: elementos para uma história. In: JODELET, D. As representações sociais. (Org.). Rio de Janeiro: EDUERJ. 2001. p. 45-66.
MOSCOVICl, S. Representações sociais: investigações em psicologia social. 11. ed. Petrópolis: Vozes, 2015.

OLIVEIRA, L. V. Leitura e escrita: representações sociais de professores, estudantes, pedagogas e diretoras da educação básica. 2019. 291 f. Tese (Doutorado em Educação) - Universidade Estadual de Maringá, Programa de PósGraduação em Educação, Maringá, PR, 2019.

SANTOS, A. C. As representações dos sujeitos escolares sobre a circularidade de saberes da biblioteca. 2013. 96 f. Dissertação (Mestrado em Educação) - Universidade do Estado do Pará, Belém, 2013.

TRAVAGLIA, L. C. Gramática ensino plural. 5. ed. São Paulo: Cortez, 2011.

VIGOTSKI, L. S. Pensamento e Linguagem. 2. ed. São Paulo: Martins Fontes, 2000.

ZUIN, P. B.; REYES, C. R. O ensino da língua materna: dialogando com Vygotsky, Bakhtin e Freire. Aparecida, SP: Idéias \& Letras, 2010. 